\title{
Betulin induces cytochrome $c$ release and apoptosis in colon cancer cells via NOXA
}

\author{
ZHIYUAN ZHOU*, CHENFANG ZHU*, ZHONGFANG CAI, FENG ZHAO, \\ LIU HE, XIAOLOU LOU and XIAOLIANG QI
}

\begin{abstract}
Department of General Surgery, The Ninth People's Hospital Affiliated to Shanghai Jiao Tong University School of Medicine, Shanghai 200011, P.R. China
\end{abstract}

Received May 24, 2017; Accepted November 29, 2017

DOI: $10.3892 / \mathrm{ol} .2018 .8183$

\begin{abstract}
Betulin is a common triterpene that can be readily obtained from various plants, particularly birch trees, in their natural environment. Specific tumor cells are sensitive to betulin, whereas healthy cells are not. Betulin was observed to stimulate programmed cell death of various cancer cell lines; however, the precise molecular mechanism of action of betulin remains unknown. The present study used colon cancer cells, in which mass apoptosis triggered by betulin was identified, and the apoptotic process was demonstrated to occur via the activation of caspase-3 and -9 pathways. In addition, release of cytochrome $\mathrm{c}$ was detected. Furthermore, the pro-apoptotic member of the Bcl-2 protein family, NOXA, was induced following treatment with betulin, and the downregulation of NOXA markedly suppressed the release of cytochrome $c$ and apoptosis in colon cancer cells. Conversely, the overexpression of NOXA further enhanced betulin-induced apoptosis. The present study therefore offers novel insights into the mechanism of action of the natural compound betulin against tumors.
\end{abstract}

\section{Introduction}

Betulin is a frequently occurring natural compound, abundant in trees and grasses, making up $\sim 33 \%$, in mass, of the extracts obtained from the bark of birch trees (1). It is a versatile compound that may be used in conjunction with others to form a variety of chemicals for a number of pharmacological usages, including in poison oak, as a skin irritant (1). Betulinic acid, which is derived from betulin, has been used as a cytotoxic drug to treat tumors

Correspondence to: Dr Xiaoliang Qi or Dr Xiaolou Lou, Department of General Surgery, The Ninth People's Hospital Affiliated to Shanghai Jiao Tong University School of Medicine, 639 Zhizhaoju Road, Shanghai 200011, P.R. China

E-mail: qixlx1@126.com

E-mail:xlou_lou@live.com

${ }^{*}$ Contributed equally

Key words: betulin, apoptosis, cytochrome $c$, NOXA due to its antitumorigenic abilities (2-4). The cytotoxicity of betulin has been the focus of previous studies; however, the exact mechanism of action has yet to be elucidated $(5,6)$.

The inhibition of cellular apoptosis is a key indicator that marks the initiation and progression of cancer (7). Therefore, current cancer treatments, including chemotherapy and immunotherapy, function primarily through promoting the apoptosis of tumor cells $(8,9)$. Programmed cell death may be induced via either a receptor or mitochondrial-signaling pathway. Receptor-induced apoptosis functions through intracellular signaling transmissions via death receptors, whereas the latter occurs through the destruction of mitochondria (10).

The primary regulators of mitochondrion-dependent apoptosis are $\mathrm{B}$-cell lymphoma $2(\mathrm{Bcl}-2)$ proteins (11). These signaling molecules belong to the $\mathrm{Bcl}-2$ homology 3 (BH3) family, a subset of the Bcl-2 family that contain a single BH3 domain, with $>10$ members, including NOXA and Bcl-2-interacting mediator of cell death (Bim), which respond well to single and mixed pro-apoptotic signals $(12,13)$. They are able to trigger apoptosis by inducing the apoptosis regulator Bcl-2-associted X protein (Bax), while counteracting the effect of the anti-apoptotic gene Bcl-2, in addition to stimulating caspases resulting in mitochondrial dysfunction $(14,15)$.

The aim of the present study was to investigate the antitumor properties of betulin against human colon cancer cells and elucidate its underlying mechanisms of action at a molecular level.

\section{Materials and methods}

Cell culture. The colon cancer cell lines HCT116 and HT29, and the normal human colon epithelial cell line CCD $841 \mathrm{CoN}$ were purchased from the American Type Culture Collection (Manassas, VA, USA), and cultured in Dulbecco's modified Eagle's medium containing $100 \mathrm{U} / \mathrm{ml}$ penicillin, $10 \%$ bovine serum and $100 \mu \mathrm{g} / \mathrm{ml}$ streptomycin in a humidified incubator with $5 \% \mathrm{CO}_{2}$ at $37^{\circ} \mathrm{C}$. Betulin was obtained from Sigma-Aldrich; Merck KGaA (Darmstadt, Germany).

Analysis of cell viability and colony formation. An MTT assay was used to determine cell viability. Briefly, 1,000 cells were seeded into each well of 96 -well plate and the formazan grains formed by viable cells were solubilized with $200 \mathrm{ml}$ dimethyl 
sulfoxide. The color intensity was measured at $550 \mathrm{~nm}$ via a 96-well plate reader (Thermo Fisher Scientific, Inc., Waltham, MA, USA). In the crystal violet staining assay, a total of 5,000 cells were placed in in 12 -well plates for 14 days at $37^{\circ} \mathrm{C}$ and then stained with $1 \%$ crystal violet for $30 \mathrm{sec}$ at room temperature (Sigma-Aldrich; Merck KGaA).

Nuclear staining using Hoechst 33258. Colon cancer cells were fixed using $4 \%$ paraformaldehyde following betulin treatment $(10 \mathrm{mg} / \mathrm{mL})$. Hoechst $33342(10 \mu \mathrm{g} / \mathrm{ml}$; Sigma-Aldrich; Merck KGaA) was used to stain cells for $10 \mathrm{~min}$ at $37^{\circ} \mathrm{C}$. Following this, cells were washed with PBS 2 times and a fluorescent microscope at x200 magnification (DM1000 LED; Leica Microsystems, Ltd., Milton Keynes, UK) was used to observe the apoptotic cells. Cells which exhibited nuclear fragmentation and chromatin condensation were considered to be apoptotic cells, and cells that exhibited round and regular nuclei were considered to be normal cells. Twenty fields were randomly selected in each slide to count apoptotic cells.

Flow cytometric analysis. Flow cytometric analysis was performed as previously outlined by He et al (16). Briefly, cells were re-suspended in cold binding buffer from the Alexa Flouor $^{\circledR} 488$ Annexvin V Cell Apoptosis kit (Invitrogen; Thermo Fisher Scientific, Inc., Waltham, MA, USA) (200 $\mu \mathrm{l})$, followed by the addition of propidium iodide $(5 \mu \mathrm{l})$ and Annexin V-fluorescein isothiocyanate (10 $\mu \mathrm{l})$ (Invitrogen; Thermo Fisher Scientific, Inc.). Cells were incubated at room temperature for $15 \mathrm{~min}$ in darkness, and $300 \mu \mathrm{l}$ binding buffer from the Alexa Flouor ${ }^{\circledR} 488$ Annexvin V Cell Apoptosis kit was added to block the reaction. A flow cytometer was used (BD Biosciences, San Jose, CA, USA). Cells which were positive for Annexin- $\mathrm{V}$ were considered to be apoptotic cells. Data was analyzed using BD AccuriTM C6 Software (version 1.0.264.21; BD Biosciences).

Reverse-transcription-quantitative polymerase chain reaction $(R T-q P C R)$. Total RNA was extracted from betulin-treated cells using a Mini RNA Isolation II kit (Zymo Research Corp., Irvine, CA, USA), according to the manufacturer's protocol. Superscript II reverse transcriptase was used to create cDNA from the total RNA. Real-time PCR with SYBR Green (Invitrogen; Thermo Fisher Scientific, Inc.) was conducted as previously described (17). The thermocycling conditions were as follows; $94^{\circ} \mathrm{C} 5 \mathrm{~min}, 94^{\circ} \mathrm{C} 30$ second, $58^{\circ} \mathrm{C} 1 \mathrm{~min}$, $72^{\circ} \mathrm{C} 2 \mathrm{~min}, 72^{\circ} \mathrm{C} 10 \mathrm{~min}$. The following primers were used: p53-upregulated modulator of apoptosis (PUMA), 5'-CGA CCTCAACGCACAGTACGA-3' (forward) and 5'-AGGCAC CTAATTGGGCTCCAT-3' (reverse); Bim, 5'-GGAGACGAG TTTAACGCTTAC-3' (forward) and 5'-CAAGCAAAATGT CTGCATGG-3' (reverse); NOXA, 5'-GCTGGAAGTCGA GTGTGCTA-3' (forward) and 5'-CCTGAGCAGAAGAGT TTGGA-3' (reverse); Bcl-2-associated death promoter (BAD), 5'-CGGAGGATGAGTGACGAGTT-3' (forward) and 5'-GAT GTGGAGCGAAGGTCACT-3' (reverse); $\beta$-actin, 5'-GAC CTCACAGACTACCTCAT-3' (forward) and 5'-AGACAG CACTGTGTTGGCTA-3' (reverse). The mRNA levels were quantified using the $2^{-\Delta \Delta \mathrm{Cq}}$ method (17). $\beta$-actin was used as the internal control. Experiments for each gene were conducted in triplicate.
Small-interfering RNA (siRNA) and plasmid transfection. NOXA siRNA duplexes 200 pmol (5'-GUAAUUAUUGAC ACAUUUCUU-3') and control scrambled siRNA 200 pmol (Guangzhou RiboBio Co., Ltd., Guangzhou, China) or pCDNA and pcDNA-NOXA plasmid (Guangzhou RiboBio Co., Ltd.) were introduced into HCT116 cells with Lipofectamine ${ }^{\circledR} 2000$ (Invitrogen; Thermo Fisher Scientific, Inc.) for 1 day and were treated with $10 \mu \mathrm{g} / \mathrm{ml}$ betulin for $24 \mathrm{~h}$ following transfection.

Caspase evaluation. Cells were treated with betulin $(10 \mathrm{mg} / \mathrm{ml})$ for $0,48,12$ and $24 \mathrm{~h}$. Cell lysates $(50 \mu \mathrm{g})$ were incubated with $200 \mathrm{nM}$ fluorigenic substrates for caspase-3, -8 and -9 (N-acet yl-Asp-Glu-Val-Asp-7-amido-4-trifluoromethylcoumarin, N-acetyl-Ile-Glu-Thr-Asp-7-amido4-trifl uoromethylcoumarin and N-acetyl-Leu-Glu-HisAsp-7-amido-4-trifluoromethylcoumarin, respectively) (Sigma-Aldrich; Merck KGaA) in a buffer solution comprising 20 mM 4-(2-hydroxyethyl)-1-piperazine-ethanesulfonic acid (pH 7.4), $100 \mathrm{mM} \mathrm{NaCl}, 0.1 \%$ 3-[(3-cholamidopropyl) dimethylammonio]-1-propanesulfonate, dithiothreitol (10 mM) and $10 \%$ sucrose at $37^{\circ} \mathrm{C}$ for $1 \mathrm{~h}$. Following incubation, fluorescence was determined using a Biotek microplate reader (BioTek Instruments, Inc., Winooski, VT, USA) at emission and excitation at $535 \mathrm{~nm}$ and $405 \mathrm{~nm}$, respectively.

Cytochrome c analysis. A $10 \mu \mathrm{g} / \mathrm{ml}$ concentration of betulin was administered to HCT116 cells for $24 \mathrm{~h}$. The isolated cytoplasm components and mitochondrial particles were analyzed using the Mitochondrial Fractionation kit (Active Motif, Inc., Carlsbad, CA, USA), according to the manufacturer's protocol. The total protein concentrations was calculated using a BCA assay (Thermo Fisher Scientific, Inc.). Western blotting was performed to evaluate cytochrome $c$ expression in the cytoplasm and mitochondria. Briefly, protein was extracted using radioimmunoprecipitation assay buffer (Abcam, Cambridge, $\mathrm{UK})$. In total, $50 \mu \mathrm{g}$ protein was loaded into each well $(12.5 \%$ Bis-Tris gel). Proteins were then transferred to a polyvinylidene difluoride membrane. The enhanced chemiluminescence western blotting detection system (Tanon 4200; Tanon Science and Technology Co., Ltd., Shanghai, China) and each band was analyzed following western blotting, using Quantity One software (version 1.03; Tanon Science and Technology Co., Ltd.). Following treatment with betulin, cells were fixed with $4 \%$ paraformaldehyde solution for 10-20 min at room temperature and incubated in PBS containing $0.1 \%$ Tween-20 and 5\% normal goat serum for $30 \mathrm{~min}$ at room temperature, followed by antibody incubation in a diluted solution in the ratio of cytochrome $c$ (dilution 1:200) at room temperature for $3 \mathrm{~h}$. Primary antibodies included cleaved caspase-9 (catalog no. 20750, dilution 1:1,000; Cell Signaling Technology, Inc., Danvers, MA, USA), cleaved caspase-3 (catalog no. 9661, dilution 1:1,000; Cell Signaling Technology, Inc.), cleaved caspase-8 (catalog no. 9496, dilution 1:1,000; Cell Signaling, Danvers, MA, USA), cytochrome $c$ (catalog no. ab13575, dilution 1:1,000; Abcam, Shanghai, China), and NOXA (catalog no. ab23563, dilution 1:1,000; Abcam, Shanghai, China). Horseradish peroxidase-conjugated secondary antibodies included goat anti-rabbit IgG (catalog no. ab6702, dilution 1:5,000; Abcam, Shanghai, China) and goat anti-mouse IgG (catalog no. ab6708, dilution 1:5,000; Abcam, Shanghai, China) were incubated for $1 \mathrm{~h}$ at room temperature. 
A

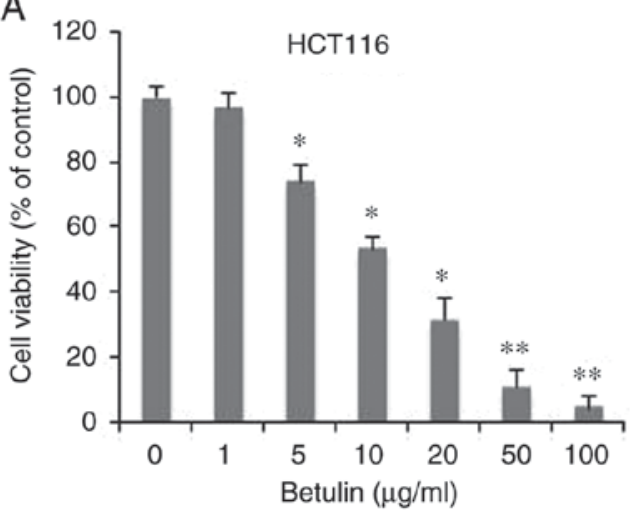

C
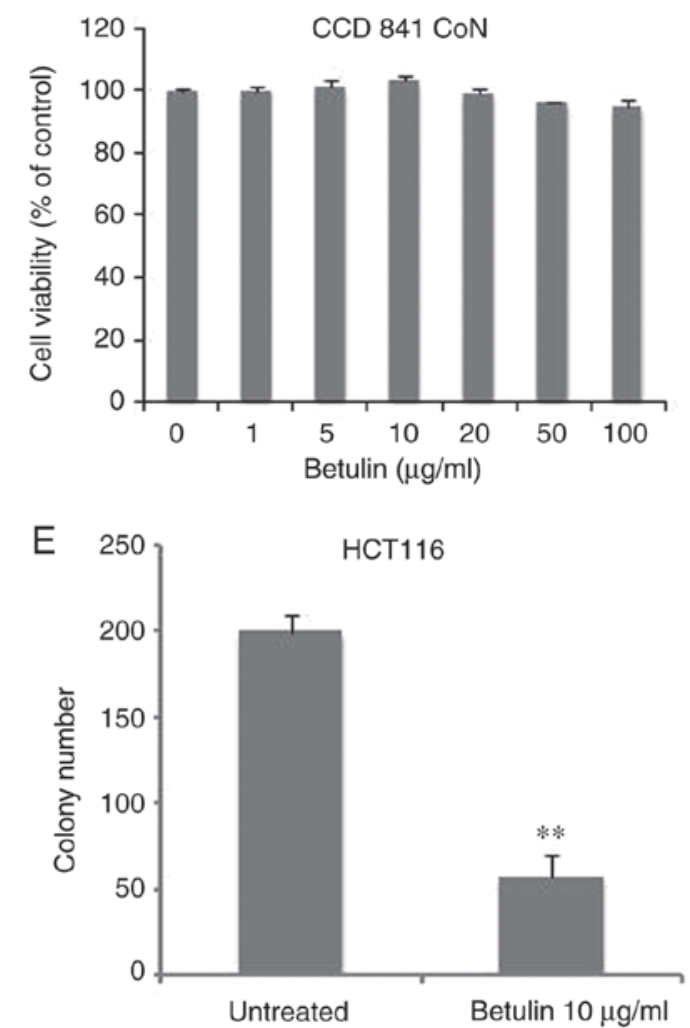

B

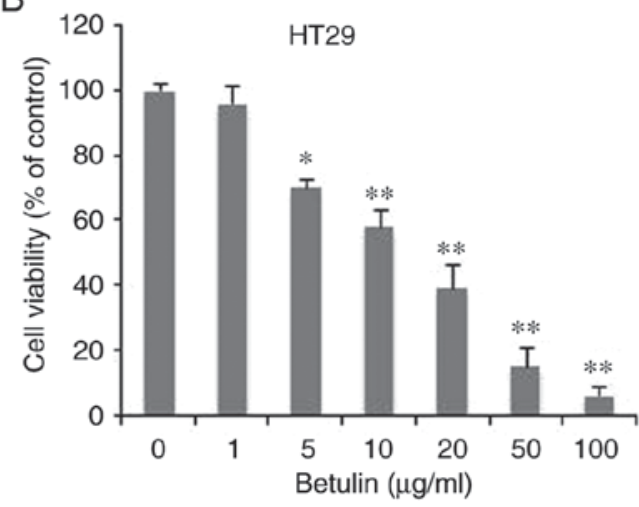

D

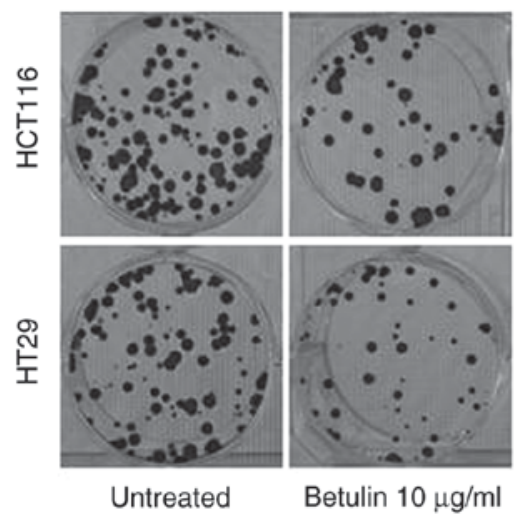

F

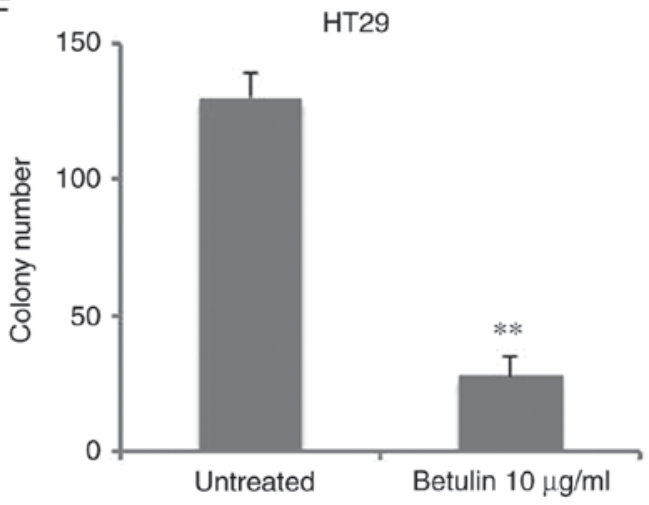

Figure 1. Effect of betulin on the viability of colon cancer cells. (A) HCT116, (B) HT29 and (C) CCD 841 CoN cells were incubated with betulin (range, $0-100 \mu \mathrm{g} / \mathrm{ml}$ ) for $72 \mathrm{~h}$. Subsequently, an MTT assay was performed to determine cell viability. (D) A cell colony formation assay was performed by plating betulin-treated $(10 \mu \mathrm{g} / \mathrm{ml}, 48$ h) 5000 HCT116 and HT29 cells onto 12-well plates. Cells were stained with crystal violet for 14 days. Quantification of colony numbers in (E) HCT116 and (F) HT29 cells. Data are presented as the mean \pm standard deviation from three independent experimental repeats. "P $<0.01$, ${ }^{* *} \mathrm{P}<0.001$ vs. untreated cells.

Immunofluorescence staining was performed using anti-mouse antibodies (cat. no. F0111; dilution 1:500; Dako; Agilent Technologies, Inc., Santa Clara, CA, USA) conjugated with fluorescein isothiocyanate. Subsequently, cells were washed with PBS (containing $0.1 \%$ Tween) and nuclei were treated with DAPI staining (dilution 1:5,000) for $10 \mathrm{~min}$. Immunofluorescence staining was visualized using an Olympus microscope (magnification, $\mathrm{x} 40$ ). All experiments were performed in triplicate.

Statistical analysis. Data are presented as the mean \pm standard deviation and analyzed with Student's t-test or one-way analysis of variance (ANOVA), Tukey's multiple comparison was applied as a post hoc test following ANOVA. Statistical differences were determined with SPSS 22.0 (IBM Corp., Armonk, NY, USA). $\mathrm{P}<0.05$ was considered to indicate a statistically significant difference.

\section{Results}

Cytotoxicity of betulin in colon cancer cells. In order to determine the antitumor capabilities of betulin against colon cancer cell lines, an MTT assay was conducted to examine the cytotoxic effects of betulin in HCT116 and HT29 cells. As Fig. 1A demonstrates, treatment with betulin significantly decreased the viability of HCT116 cells at concentrations $>5 \mu \mathrm{g} / \mathrm{ml}$, reaching $>90 \%$ at $100 \mu \mathrm{g} / \mathrm{ml}$ following $72 \mathrm{~h}$ of incubation. Betulin treatment of the other cell line examined, HT29, also exhibited a 

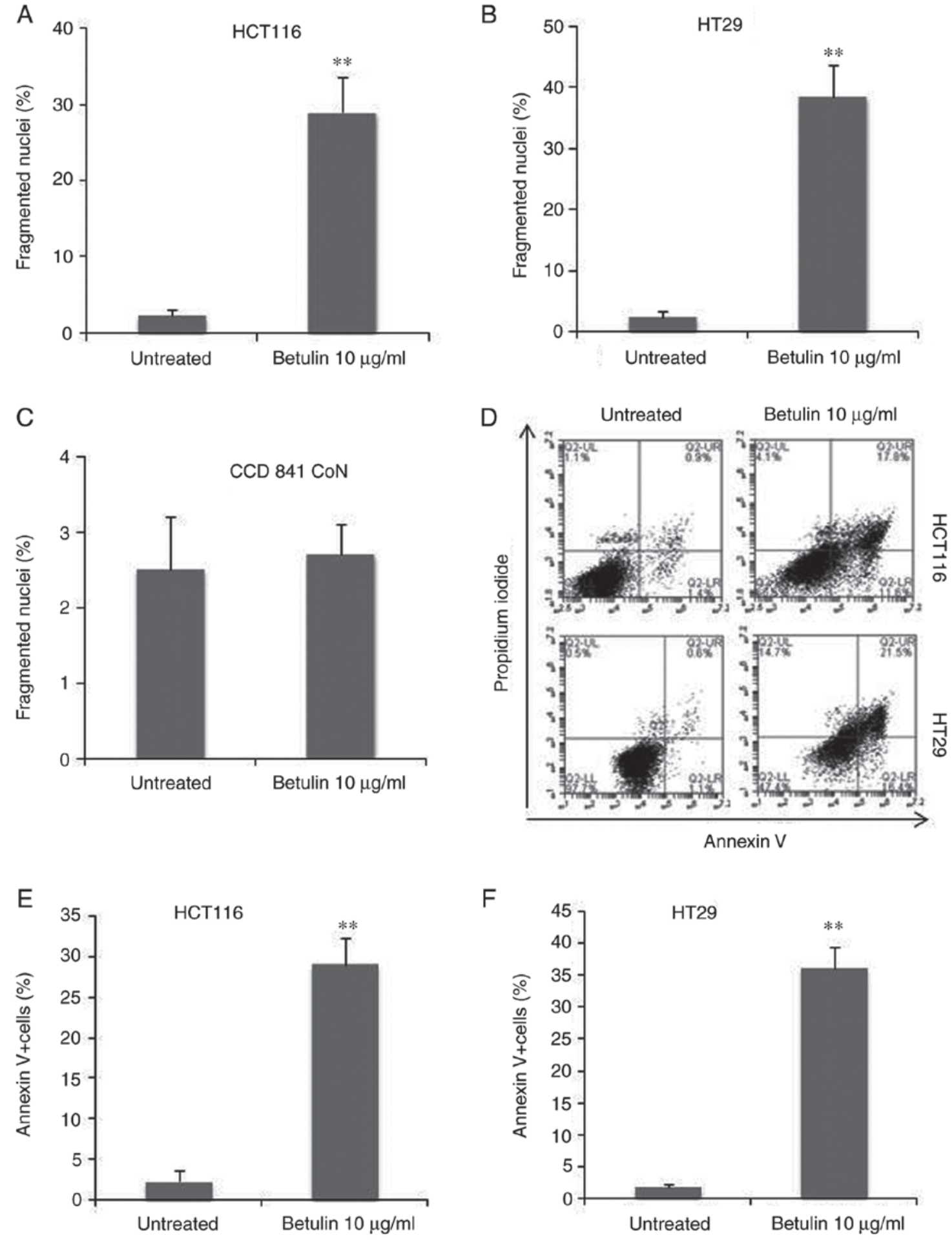

Figure 2. Betulin induces apoptosis in human colon cancer cells. (A) HCT116 cells, (B) HT29 cells and (C) CCD 841 CoN cells were treated with betulin $(10 \mu \mathrm{g} / \mathrm{ml})$ for $48 \mathrm{~h}$. The condensed and fragmented nuclei in the apoptotic process were counted for further analysis. (D) The Annexin V/propidium iodide staining was applied in attached cells, followed by flow cytometric analysis. The Annexin V+ cell ratio (indicated in the two right quadrants) in (E) HCT116 and (F) HT29 cells was plotted. ** $\mathrm{P}<0.001$ vs. untreated cells.

similar dose-dependent effect (Fig. 1B). The median lethal dose value of betulin $(\sim 10 \mu \mathrm{g} / \mathrm{ml})$ was similar for HCT116 and HT29 cells. Consequently, the standard concentration of betulin for subsequent experiments was set at $10 \mu \mathrm{g} / \mathrm{ml}$. However, this dosage had limited effect on the normal human colon epithelial cells CCD 841 CoN (Fig. 1C). Additionally, the long-term colony-formation capacities of the two colon cancer cell lines following betulin treatment were determined using crystal violet staining. Compared with the untreated group, betulin-treated cells produced $>60 \pm 5.3 \%$ fewer colonies in HCT116 and HT29 cells (Fig. 1D). However, HT29 cells were more sensitive to the effects of betulin (Fig. 1E-F). These results demonstrated that betulin is cytotoxic towards colon cancer cells.

Betulin induces apoptosis in colon cancer cells. In order to examine the association between decreasing cell viability 

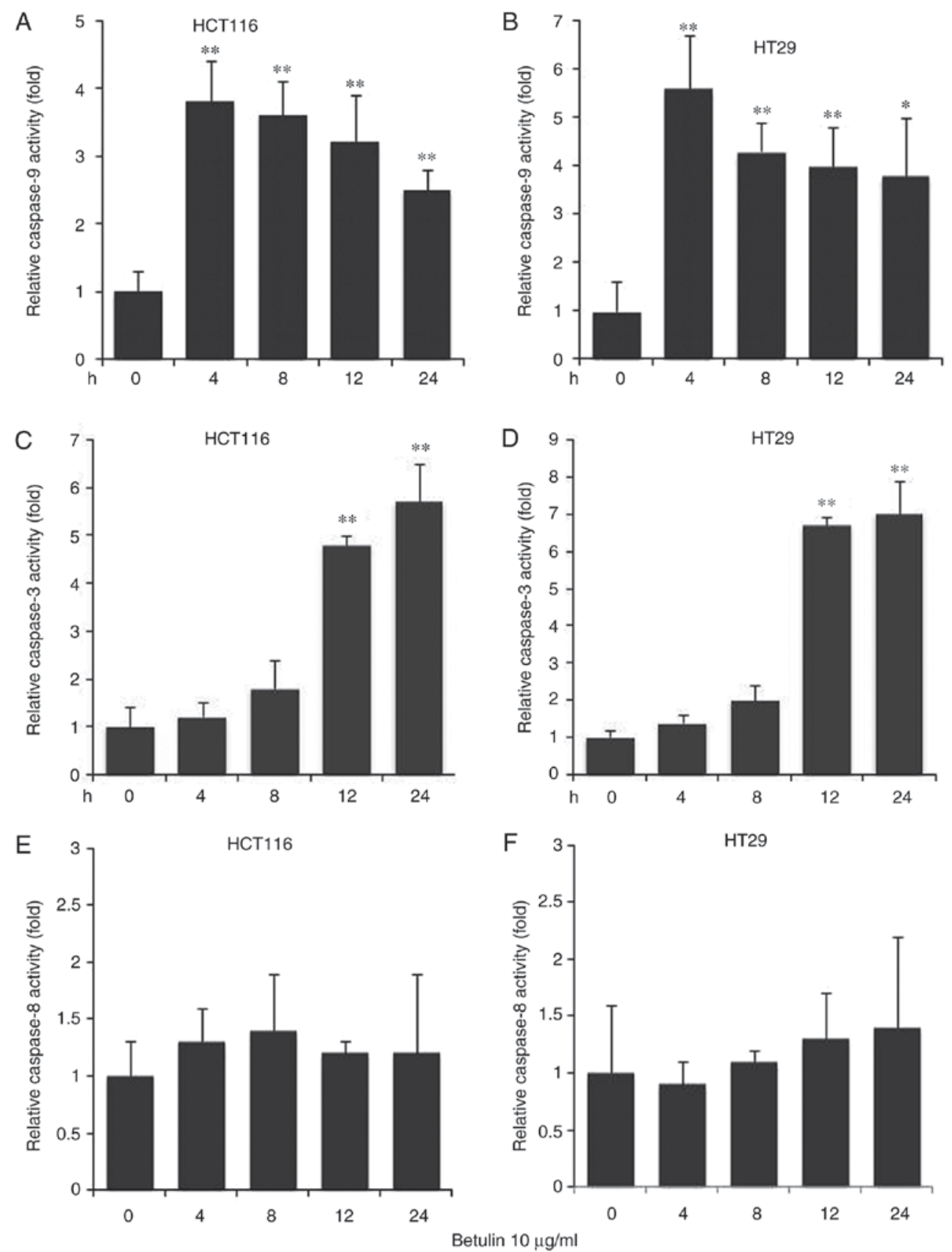

Figure 3. Caspase- $9,-3$ and -8 activation in the apoptosis of colon cancer cells. Cell lines were treated with betulin $(10 \mu \mathrm{g} / \mathrm{ml})$ for $0,4,8,12$ and $24 \mathrm{~h}$. Cell-free caspase-9 activity of (A) HCT116 and (B) HT29 cells was analyzed using N-acetyl-Leu-Glu-His-Asp-7-amido-4-trifluoromethylcoumarin. Caspase-3 activity of (C) HCT116 and (D) HT29 cells was analyzed using N-acetyl-Asp-Glu-Val-Asp-7-amido-4-trifluoromethylcoumarin. Caspase-8 activity of (E) HCT116 and (F) HT29 cells was examined using N-acetyl-Ile-Glu-Thr-Asp-7-amido-4-trifluoromethylcoumarin. Data from the control groups (untreated cells) were not shown. Results are presented as the mean \pm standard deviation of three experiments. ${ }^{*} \mathrm{P}<0.01,{ }^{* *} \mathrm{P}<0.001$, treatment in indicated time point vs. $0 \mathrm{~h}$ treatment.

and programmed cell death, the preset study examined and compared the apoptotic attributes of HCT116 and HT29 cells following betulin treatment. First, the results of the present study identified an increase in the number of floating cells following betulin treatment compared with the untreated groups, which was suggestive of apoptosis due to HCT116 cells being adherent. This was also accompanied by several other typical characteristics of apoptotic cell death, including the rounding of cells and the emergence of irregular bulges in cell membranes (data not shown). Secondly, HCT116 and HT29 cells with condensed chromatin and micronucleation following nuclear staining with Hoechst 33258 were counted with and without treatment with $10 \mu \mathrm{g} / \mathrm{ml}$ betulin. Betulin treatment induced between $30 \pm 3.4 \%$ and $40 \pm 4 \%$ fragmented nuclei (+) cells after $48 \mathrm{~h}$ in HCT116 and HT29 cells, respectively (Fig. 2A and B). However, this dosage had limited effect on the normal human colon epithelial cells CCD 841 CoN (Fig. 2C). Furthermore, apoptosis was assessed using Annexin V analysis; the results demonstrated that $>30 \%$ of HCT116 and HT29 cells were Annexin V (+) $48 \mathrm{~h}$ after being treated with betulin compared with their respective control groups (Fig. 2D-F). These findings indicated that programmed cell death may be induced by betulin in human colon cancer cells. 
A

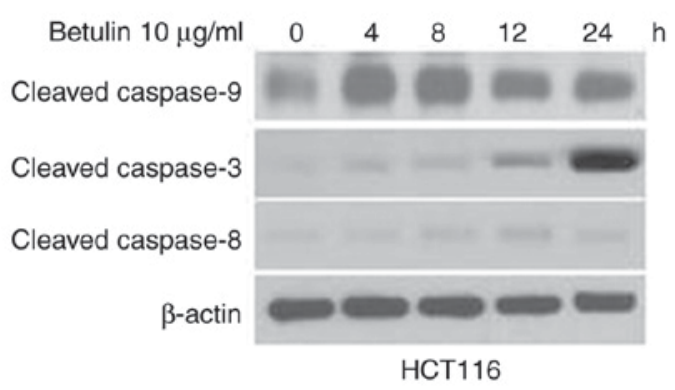

B

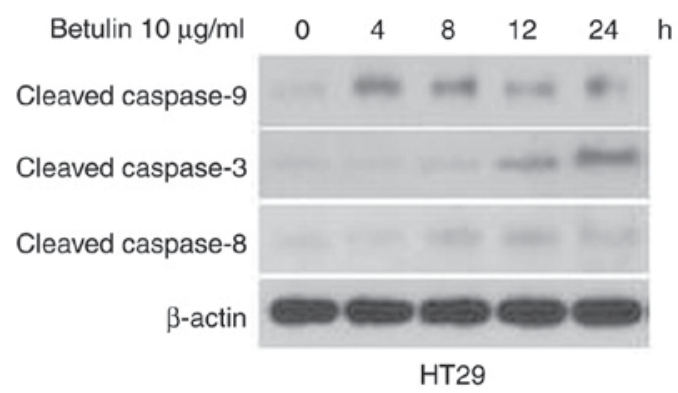

Figure 4. Cleaved caspase- $9,-3$ and -8 expression in betulin-induced apoptosis in human colon cancer cells. HCT116 (upper) and HT29 (lower) cells were treated with $10 \mu \mathrm{g} / \mathrm{ml}$ betulin for $0,4,8,12$ and $24 \mathrm{~h}$. Cleaved caspase- 9 , -3 and -8 expression in (A) HCT116 and (B) HT29 were examined using western blotting.

Betulin induces the release of caspase-3 and -9 , and cytochrome $c$. The effect of betulin on activating the upstream effectors caspase- 8 and -9 , and the downstream effector caspase-3 was investigated in colon cancer cells. A significantly increased level of caspase-9 was observed in betulin-treated cells after $4 \mathrm{~h}$ in comparison with the respective negative control groups; thereafter, the levels of capspase-9 gradually decreased (Fig. 3A and B). A significant increase in the activity of caspase- 3 was not detected until after $8 \mathrm{~h}$ of betulin treatment (Fig. 3C and D); however, the increase in caspase- 3 activity was observed from 4 to $24 \mathrm{~h}$ of betulin treatment. However, the level of relative caspase- 8 activity did not alter significantly throughout the experiment in the cancer cell lines examined (Fig. 3E and F). Western blot analysis confirmed the increased level of cleaved caspase-9, -3 and -8 following betulin treatment in HCT116 and HT29 cells (Fig. 4). As betulin was demonstrated to stimulate caspase- 9 activation, the present study proceeded to examine the releasing level of cytochrome $c$ in HCT116 cells following betulin treatment. Using immunoblotting and immunofluorescence techniques, the results of the present study demonstrated that cytochrome $c$ was released in the cytosolic area of cells following treatment with betulin; furthermore, its level decreased in the mitochondrial fraction following $24 \mathrm{~h}$ treatment with betulin in contrast with that in of the control group (Fig. 5A and B). These results indicated that betulin was able to activate caspase- 9 and -3 , in addition to releasing cytochrome $c$ in colon cancer cells.

NOXA mediates apoptosis in betulin-treated colon cancer cells. In order to determine the possible effect of the BH3-only proteins in betulin-induced apoptosis, the relative mRNA levels of its major members in betulin-treated HCT116
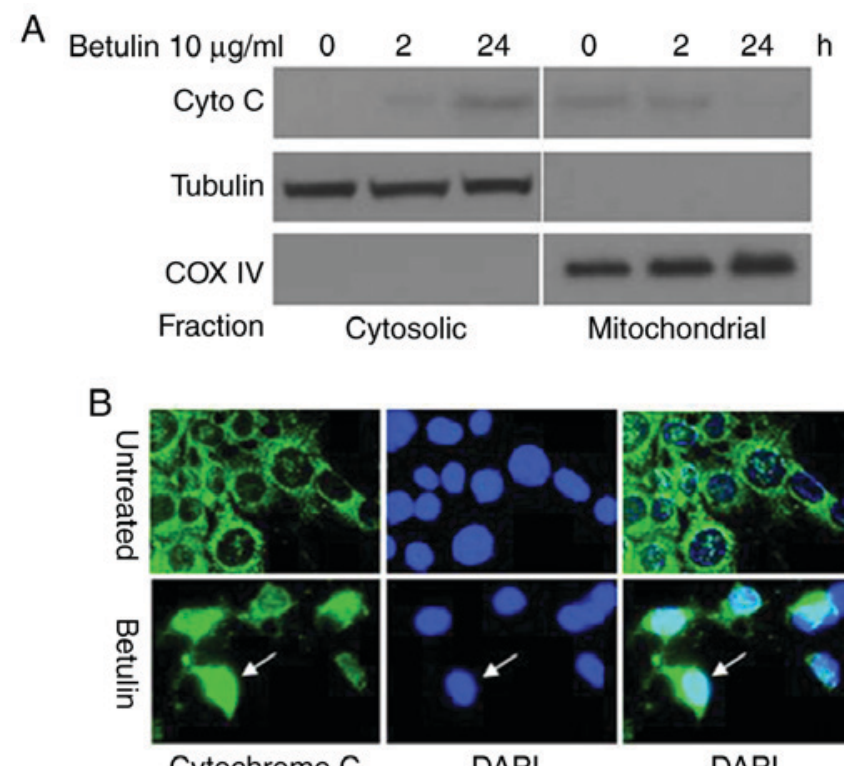

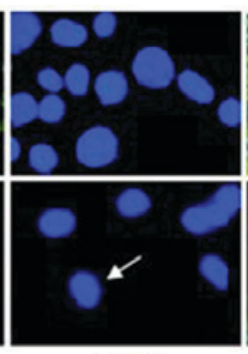

DAPI

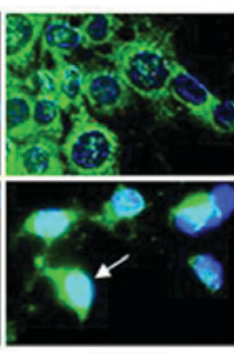

DAPI
Figure 5. Release of cytochrome $c$ in apoptosis induced by betulin in HCT116 cells. Cells were treated with betulin $(10 \mu \mathrm{g} / \mathrm{ml})$ for 0,2 and $24 \mathrm{~h}$ (A) Cytosolic and mitochondrial fractions isolated from cells. The distribution of cytochrome $c$ was analyzed with western blotting. The control groups for fractionation were $\alpha$-tubulin and cytochrome oxidase subunit IV. (B) Immunofluorescent staining of HCT116 cells with cytochrome $c$ (green) and DAPI (blue). Cyto C, cytochrome $c$; COX IV, cytochrome oxidase IV.

colon cancer cells were determined using RT-qPCR. Results demonstrated a markedly increased mRNA level of NOXA and Bim, whereas PUMA and BAD remained unchanged following betulin treatment (Fig. 6A). Notably, NOXA was induced almost 15 -fold at the mRNA level and significantly increased at the protein level as demonstrated using western blot analysis (Fig. 6B). siRNA against NOXA was employed to investigate whether NOXA serves a role in betulin-induced apoptosis in colon cancer cells. The fragmented nuclei (+) cell percentage and cytochrome $c$ release following betulin treatment was significantly abrogated in the NOXA siRNA group compared with the scrambled siRNA group (Fig. 6C and D). Furthermore, overexpression of NOXA further enhanced the betulin-induced apoptosis (Fig. 6E and F). These results suggested that NOXA mediated apoptosis in betulin-treated colon cancer cells.

\section{Discussion}

Vinca alkaloids and taxanes are two categories of naturally occurring compounds that are used as chemotherapeutic agents. Vinblastine and vincristine, derived from Catharanthus roseus, were the first to be applied in a clinical setting in 1958, which were followed by various derivatives including vindesine and vinflunine (18). Betulin is in same class as taxanes known as isoprenoids (19). Betulin is recognized as a positive agent against human immunodeficiency virus due to its ability to suppress the replication process in human immunodeficiency virus (20). Consequently, an increasing number of studies are now focusing on its antitumor potential. In the present study, it was demonstrated that the naturally obtainable compound betulin was able to activate apoptosis in human colon cancer 
A

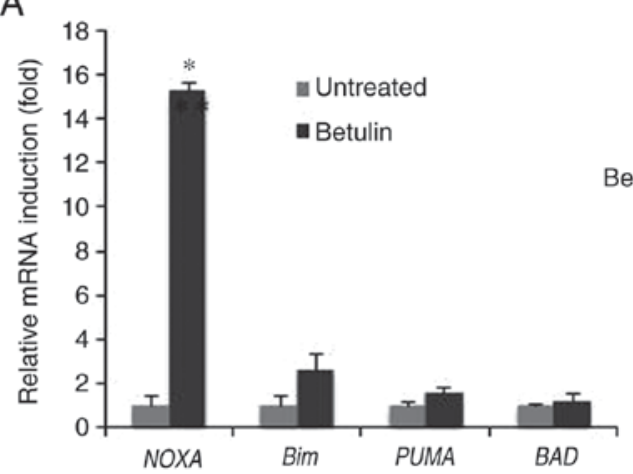

B

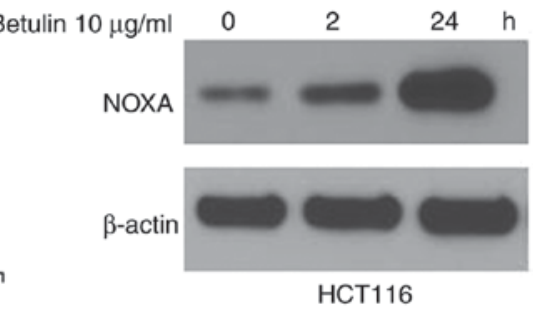

C

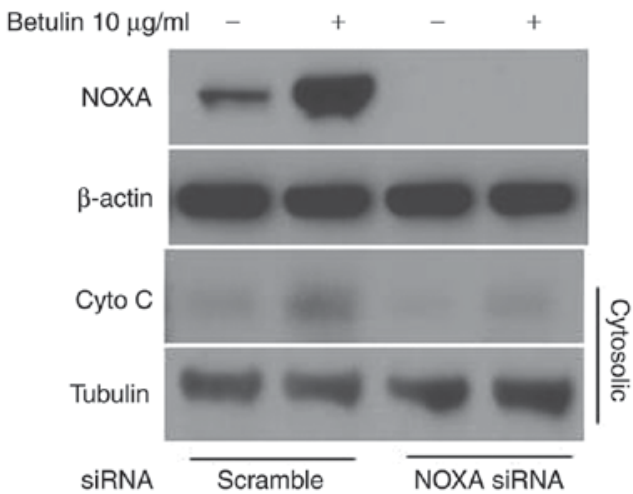

D
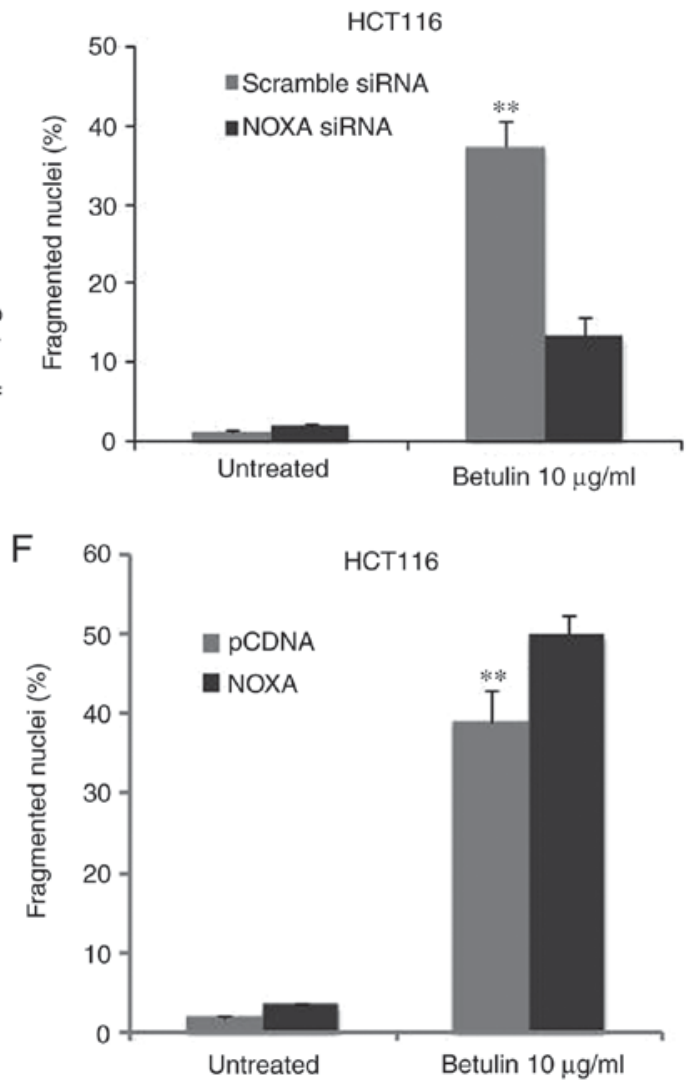

Figure 6. Induction of NOXA-mediated betulin-induced apoptotic cell death in HCT116 cells. The HCT116 cell line was treated with betulin (10 $\mu \mathrm{g} / \mathrm{ml})$ for $24 \mathrm{~h}$. (A) The mRNA level of the indicated gene was evaluated using RT-qPCR. " $\mathrm{P}<0.01$ vs. untreated cells. (B) The protein status of NOXA was evaluated using western blotting in HCT116 cells following betulin $(10 \mu \mathrm{g} / \mathrm{ml})$ treatment at 0,2 and $24 \mathrm{~h}$. Transfection of HCT116 cells with NOXA siRNA was performed for $24 \mathrm{~h}$ prior to betulin treatment $(10 \mu \mathrm{g} / \mathrm{ml})$ for the indicated times. (C) Cytosolic fractions isolated from HCT116 cells. The distribution of cytochrome $c$ was analyzed using western blotting. The change in NOXA protein level from whole cell lysate confirmed a successful knockdown. (D) The number of condensed and fragmented nuclei was determined to evaluate apoptosis. Transfection of HCT116 cells with pCDNA-NOXA for $24 \mathrm{~h}$ was followed by betulin $(10 \mu \mathrm{g} / \mathrm{ml}, 24 \mathrm{~h})$ treatment. (E) The protein expression of NOXA was analyzed using western blotting. (F) The number of condensed and fragmented nuclei was determined to evaluate the apoptosis. ${ }^{* *} \mathrm{P}<0.001$ vs. untreated cells.

cells via the caspase- 3 and -9 activation pathways, additionally releasing cytochrome $c$. Furthermore, NOXA was markedly induced in comparison with several $\mathrm{BH} 3$ proteins following betulin treatment. Furthermore, knockdown of NOXA also significantly abrogated the betulin-induced apoptosis in colon cancer cells. Therefore, the results of the present study contribute to the overall understanding of the mechanism of programmed cell death stimulated by betulin in human colon cancer cells.

A number of studies have previously demonstrated that programmed cell death is a key procedure in the mechanism of how chemotherapeutic agents act to destroy tumor cells (21). Protein cleavage may be induced via activation of caspases, which leads to apoptosis. Caspase activation occurs one of two ways: i) Through the activation of death receptors on the cell surface, which induces the upstream caspase- 8 and therefore results in the activation of the downstream caspase-3 and -7; or ii) through the mitochondria, by the release of cytochrome $c$, which activates the apoptotic protease apoptotic protease-activating factor 1 (Apaf-1), leading to the activation of caspase-9 (22-24). Through examination of the caspase-mediated process, the present 
study demonstrated that the apoptosis induced by betulin in human colon cancer cells is not, to the best of our knowledge, associated with other external apoptotic pathways, which is consistent with the effect of betulin in other types of tumor cell (25)

The Bcl-2 family protein controls the permeabilization procedures of the outer membrane of mitochondria and also regulates the release of cytochrome $c$. Previous studies have identified that that the function of and interactions between different proteins within the Bcl-2 family are restricted, which also provides insight into the activation of Bax and Bcl-2 homologous antagonist killer $(26,27)$. At present, only Bid and Bim have been identified as the $\mathrm{BH} 3$ proteins capable of interacting directly with Bax, whereas other family members, including BAD, Puma and NOXA, exhibit their functions indirectly, i.e., via 'sensitization' or 'derepression' and exclusive interactions with protective Bcl-2-like members. Consequently, various members of the BH3 domain-only group exhibit differences in their response to stimuli and in the pathways with which they are capable of regulating (28). The results of the present study demonstrated that the induction of NOXA is necessary for betulin-induced apoptotic cell death and the release of cytochrome $c$ in colon cancer cells. On the basis of the effect of NOXA on mediating the permeabilization process of the outer mitochondrial membrane $(29,30)$, our hypothesis is that the NOXA-dependent action of betulin-induced apoptosis is common in colon cancer cells. As there was a small increase in cytochrome $c$ in the cytosolic fraction following NOXA knockdown, other mechanisms may also be involved. The limitation of the present study is the focus on the short-term effect of betulin on colon cancer cells; however, the long-term effect in vivo and in vitro require further study.

In conclusion, the results of the present study demonstrated the antitumor abilities of betulin by triggering apoptosis in human colon cancer cells. Cytochrome $c$ was also released and, together with the subsequent activation of caspases, apoptosis was also induced via the mitochondrial apoptotic pathway. The induction of NOXA also served a role in the apoptotic response of colon cancer cells following betulin treatment. The results of the present study have provided a novel mechanistic insight into this type of naturally occurring chemical compound as a cancer therapeutic and therefore has the potential to contribute to overall understanding and the future development of betulin as a novel cancer therapeutic.

\section{Acknowledgements}

Not applicable.

\section{Funding}

The present study was supported by a grant from the Project of the Shanghai Municipal Commission of Health and Family Planning (grant no. 201440355).

\section{Availability of data and materials}

The analyzed data sets generated during the study are available from the corresponding author, on reasonable request.

\section{Authors' contributions}

Conception and design, XQ; development of methodology: ZZ, CZ, ZC, FZ, LH and XL; analysis and interpretation of data, ZZ, CZ, ZC; writing, review, and/or revision of the manuscript, $\mathrm{ZZ}$ and $\mathrm{XQ}$.

\section{Ethics approval and consent to participate}

Not applicable.

\section{Consent for publication}

Not applicable.

\section{Competing interests}

The authors declare that they have no competing interests.

\section{References}

1. Alakurtti S, Makela T, Koskimies S and Yli-Kauhaluoma J: Pharmacological properties of the ubiquitous natural product betulin. Eur J Pharm Sci 29: 1-13, 2006.

2. Gauthier C, Legault J, Lebrun M, Dufour P and Pichette A: Glycosidation of lupane-type triterpenoids as potent in vitro cytotoxic agents. Bioorg Med Chem 14: 6713-6725, 2006.

3. Kvasnica M, Sarek J, Klinotova E, Dzubak P and Hajduch M: Synthesis of phthalates of betulinic acid and betulin with cytotoxic activity. Bioorg Med Chem 13: 3447-3454, 2005.

4. Rabi T, Shukla S and Gupta S: Betulinic acid suppresses constitutive and TNFalpha-induced NF-kappaB activation and induces apoptosis in human prostate carcinoma PC-3 cells. Mol Carcinog 47: 964-973, 2008.

5. Pyo JS, Roh SH, Kim DK, Lee JG, Lee YY, Hong SS, Kwon SW and Park JH: Anti-cancer effect of betulin on a human lung cancer cell line: A pharmacoproteomic approach using 2 D SDS PAGE coupled with nano-HPLC tandem mass spectrometry. Planta Med 75: 127-131, 2009.

6. Rzeski W, Stepulak A, Szymanski M, Juszczak M, Grabarska A, Sifringer M, Kaczor J and Kandefer-Szerszen M: Betulin elicits anti-cancer effects in tumour primary cultures and cell lines in vitro. Basic Clin Pharmacol Toxicol 105: 425-432, 2009.

7. Brown JM and Attardi LD: The role of apoptosis in cancer development and treatment response. Nat Rev Cancer 5: 231-237, 2005.

8. Herr I and Debatin KM: Cellular stress response and apoptosis in cancer therapy. Blood 98: 2603-2614, 2001.

9. Whiteside TL: Apoptosis of immune cells in the tumor microenvironment and peripheral circulation of patients with cancer: Implications for immunotherapy. Vaccine 20 (Suppl 4): A46-A51, 2002.

10. Hengartner MO: The biochemistry of apoptosis. Nature 407: 770-776, 2000.

11. Youle RJ and Strasser A: The BCL-2 protein family: Opposing activities that mediate cell death. Nat Rev Mol Cell Biol 9: 47-59, 2008.

12. Thomenius MJ, Wang NS, Reineks EZ, Wang $Z$ and Distelhorst CW: Bcl-2 on the endoplasmic reticulum regulates Bax activity by binding to BH3-only proteins. J Biol Chem 278: 6243-6250, 2003.

13. van Delft MF, Wei AH, Mason KD, Vandenberg CJ, Chen L, Czabotar PE, Willis SN, Scott CL, Day CL, Cory S, et al: The BH3 mimetic ABT-737 targets selective Bcl-2 proteins and efficiently induces apoptosis via Bak/Bax if Mcl-1 is neutralized. Cancer Cell 10: 389-399, 2006.

14. Alves NL, Derks IA, Berk E, Spijker R, van Lier RA and Eldering E: The Noxa/Mcl-1 axis regulates susceptibility to apoptosis under glucose limitation in dividing T cells. Immunity 24 : 703-716, 2006.

15. Lei K and Davis RJ: JNK phosphorylation of Bim-related members of the Bcl2 family induces Bax-dependent apoptosis. Proc Natl Acad Sci USA 100: 2432-2437, 2003. 
16. He K, Zheng X, Li M, Zhang L and Yu J: mTOR inhibitors induce apoptosis in colon cancer cells via CHOP-dependent DR5 induction on 4E-BP1 dephosphorylation. Oncogene 35: 148-157, 2016.

17. Livak KJ and Schmittgen TD: Analysis of relative gene expression data using real-time quantitative PCR and the 2(Delta Delta C(T) method. Methods 25: 402-408. 2001

18. He K, Zheng X, Zhang L and Yu J: Hsp90 inhibitors promote p53-dependent apoptosis through PUMA and Bax. Mol Cancer Ther 12: 2559-2568, 2013.

19. Risinger AL, Giles FJ and Mooberry SL: Microtubule dynamics as a target in oncology. Cancer Treat Rev 35: 255-261, 2009.

20. Gershenzon J and Dudareva N: The function of terpene natural products in the natural world. Nat Chem Biol 3: 408-414, 2007.

21. Fujioka T, Kashiwada Y, Kilkuskie RE, Cosentino LM, Ballas LM, Jiang JB, Janzen WP, Chen IS and Lee KH: Anti-AIDS agents, 11. Betulinic acid and platanic acid as anti-HIV principles from syzigium claviflorum, and the anti-HIV activity of structurally related triterpenoids. J Nat Prod 57: 243-247, 1994.

22. Fulda S and Debatin KM: Extrinsic versus intrinsic apoptosis pathways in anticancer chemotherapy. Oncogene 25: 4798-4811, 2006.

23. Shi Y: Mechanisms of caspase activation and inhibition during apoptosis. Mol Cell 9: 459-470, 2002.

24. Jin Z and El-Deiry WS: Overview of cell death signaling pathways. Cancer Biol Ther 4: 139-163, 2005.
25. Riedl SJ and Salvesen GS: The apoptosome: Signalling platform of cell death. Nat Rev Mol Cell Biol 8: 405-413, 2007.

26. Li Y, He K, Huang Y, Zheng D, Gao C, Cui L and Jin YH: Betulin induces mitochondrial cytochrome $\mathrm{c}$ release associated apoptosis in human cancer cells. Mol Carcinog 49: 630-640, 2010.

27. Chen L, Willis SN, Wei A, Smith BJ, Fletcher JI, Hinds MG, Colman PM, Day CL, Adams JM and Huang DC: Differential targeting of prosurvival $\mathrm{Bcl}-2$ proteins by their $\mathrm{BH} 3$-only ligands allows complementary apoptotic function. Mol Cell 17: 393-403, 2005.

28. Kuwana T, Bouchier-Hayes L, Chipuk JE, Bonzon C, Sullivan BA, Green DR and Newmeyer DD: BH3 domains of BH3-only proteins differentially regulate Bax-mediated mitochondrial membrane permeabilization both directly and indirectly. Mol Cell 17: 525-535, 2005.

29. Strasser A: The role of BH3-only proteins in the immune system. Nat Rev Immunol 5: 189-200, 2005.

30. Chipuk JE, Bouchier-Hayes L and Green DR: Mitochondrial outer membrane permeabilization during apoptosis: The innocent bystander scenario. Cell Death Differ 13: 1396-1402, 2006. 